\title{
Approaches for Human Capital Measurement with an Empirical Application for Growth Policy
}

\author{
Rewat Thamma-Apiroam ${ }^{1}$ \\ ${ }^{1}$ Department of Economics, Faculty of Economics, Kasetsart University, Bangkok, Thailand \\ Correspondence: Rewat Thamma-Apiroam, Department of Economics, Faculty of Economics, Kasetsart \\ University, Bangkok, 10900, Thailand. Tel: 66-2579-8739. E-mail: fecoret@hotmail.com
}

Received: August 20, 2015 Accepted: September 28, 2015 Online Published: October 21, 2015

doi:10.5539/ass.v11n26p309 URL: http://dx.doi.org/10.5539/ass.v11n26p309

\begin{abstract}
This study aims at providing a theoretical concept of human capital and its measurement that have been continually developed for decades and empirically testing the casual relationships between human capital, measured by educational spending, and economic growth of Thailand. The methodologies are through literature synthesis and qualitative analysis as well as time-series quantitative analysis; the data is annually collected during the period $1980-2010$. The finding indicates that human capital can be defined in different frameworks because its definition changes over time. Nonetheless, owing to a key attribute, it should be defined on a broader view and its spillover effects should be taken into account as well. The other finding is that the standard approaches to human capital measurement are cost-based, income-based and output-based. The empirical results suggest bidirectional causality between human capital and economic growth of Thailand but much clearer for the causation running from human capital to growth. As such, the policy implication is that if the government aims to achieve the long-run economic growth, both increasing the educational opportunity and improving the quality of education are imperative.
\end{abstract}

Keywords: economic growth, government spending on education, human capital measurement, Thailand

\section{Introduction}

For centuries, human capability is deemed valuable and indispensable to the wealth of nations as pointed out by classical economists, Adam Smith, Marshall, and Say. Smith (1776) stated in "The Wealth of Nations" the importance of human capital in that one's educational expenses can be comparable to the value of expensive machinery. The role of human capabilities on economic growth has received much scholar's attention to further peruse. Schultz (1961) originated the term "human capital" and referred it to the value of human capabilities. He asserted that human capital is not dissimilar to other types of capital, at least since it could be invested in various ways such as education and training. That is, the more education and training, the higher the accumulated human capital stock is. As a result, such investment will generate higher productivity, thus raising one's earnings and resulting in higher aggregate level of production, and so does the national income. His belief influenced a great deal of successive research on human capital. Becker (1964), Arrow (1962), Mincer (1962), Uzawa (1965), and Romer (1986) among others conceptualized and emphasized its impact on one's well-being and economy in diverse analytical framework. This challenges scholars to come up with various techniques and models to transform such concepts and afterwards relate it to observable within-and-cross country data. Consequently, numerous studies center on defining and measuring human capital. Its scope and measurements, nevertheless, are subject to controversies. In part, it is because the society nowadays is much more complex than ever. Globalization, knowledge-based economy, skilled-bias technology, innovations, advances in software and cyberspace industries, better quality and longer data sets as well as newer econometric techniques make it even harder to arrive at inclusive meaning of human capital. Other than these complications, human capital is something pertaining to qualitative per se, so that previous attempts to provide its range and quantitatively measure it were not successful. Why does it so hard to come up with one agreeable meaning? Perhaps because it is diversified, dynamic by nature and it has spill-over effects on economy and society. This implies that human capital as pertaining to "social capital" should be taken into consideration when defining it comprehensively. Regardless of such difficulties, aiming to provide the definition of human capital in a practical manner by taking advantage of its evolving notions and theoretical developments is beneficial. In so doing, we may define and 
underpin practical approaches for human capital measurement. As such, in this paper, one of the main focuses is to identify approaches for human capital measurement as well as pros and cons of each approach. This is significant since the researchers are able to adopt the most suitable method for their work or even develop their own measurement of human capital based on the results. That is to say the frontier of human capital research involves identifying human capital measures as well as quantifying the human capital stock. Further, utilizing the well-measured human capital to test its validity is also crucial. One possible way is through the creation of human capital accounts, and then tries adding it into the National Accounts. Another interesting way is through investigating causal relationships between human capital and economic growth. The former should be considered the "ultimate goal" because it takes a considerable amount of time and deep understanding of human capital issues through thoroughly synthesized learning processes. The latter can be validated at once. However, at least a few complications arise. That is, what should be used as a proxy or proxies for human capital and how appropriate? Having responded to such queries is somewhat challenging and painstaking. Even so, those carefully chosen are subject to the validity check by the real data and sensible causal explanations.

However, there are a number of studies to investigate the relationship between human capitalin terms of education or educational attainment and economic growth. Mankiw, Romer, and Weil (1992) have built a model to explain the growth endogenously by extending the Solow growth model to enlist human capital as a separate input from labor. The variables in their model can be expressed in terms of efficiency unit of labor. Based on the similar production function and by assuming that the country specific shock is not correlated with the saving rate and population growth, the OLS estimation can be employed. They use average percentage of working people in secondary school to proxy for human capital investment rate and other traditional variables as well as the baseline coefficients, and establish relations among the variables through the so called Augmented Solow model. The results show this model can explain over $67 \%$ of the cross-country difference in income per capita. Also, another interesting result is that the poor countries tend to converge to the steady state faster than the rich countries. Abhijeet Chandra (2010) studied the causal relation between government expenditures on education and economic growth of India. He employed an econometric approach suitable for macroeconomic time-series data. The data are collected annually for the 1951-2009 period. To identify the direction of causality, he used both linear and non-linear Granger causality test to increase the likelihood of getting accurate results. The findings are that there exists bidirectional causality between government spending on education and economic growth. However, economic growth causes higher expenditures on education irrespective of lag numbers while expenditures on education do cause economic growth after some time lag. According to these empirical results, a policy suggestion is that the government of India should focus on increased investment in education as it is fundamental to better quality of human capital, thus leading to higher economic growth and then being followed by improved education quality. Yildirim Nurtac, Deniz Hulya, and Hepsag Aycan (2011) studied the effect of government educational expenditures on economic growth of Turkey. They argue that using the total government expenditures would lead to a possibility to ignore the positive externality of human capital so that its effect on economic growth cannot be accurately comprehended. Having employed the data over the period 1973-2009, they focus on the 19 causality analyses through augmented VAR model in levels which is superior to typical VAR in that it allows dynamic relationship among variables. The finding is that the causality only runs from growth to education, neither education to growth, nor bidirectional causation. Muhammad Imran et al. (2012) investigated the relationship between human capital and economic growth in Pakistan. Their main purpose is to find the direction of causality between the government expenditures on education and government expenditures on health as proxy for human capital and economic growth. The data are yearly from 1973 to 2002 and tested to make sure that all variables are appropriate for time-series econometric estimations. They started with unit root test, co-integration test, and Granger causality test. The model specification is in natural logarithmic form. GDP is used as dependent variable while all independent variables are one-period lagged. Other than the expenditures on education and health, debt service payment and gross fixed capital accumulation are also included to allow the interaction among variables. The results show that expenditures on health do cause GDP. Therefore, they recommend that the government of Pakistan should pay special attention to public's health spending. Sovathana Sokhom (2012) examined how intangible human capital impacts economic growth in the less developed countries (LDCs) by taking Cambodia as a case study. The aim of his study is to understand the role of intangible human capital on the economic development and growth in LDCs, especially Cambodia although recent studies indicate a strong positive relationship between human capital and social capital and economic development/growth. To examine whether such conclusion holds true in LDCs, the likert scale to measure the self-esteem and motivation is used as the quantitative tool. This is a common method in psychology because self-esteem and motivation are thought to be an apparatus to gauge part of intangible human capital within the political economy framework. That is to say the higher self-esteem and motivation, the higher economic growth is. Through the ordinal scale, t-test and another test 
are carried out to compare the satisfaction's average scores after the training program. According to the scores from 133 observations for control groups and 139 for treatment groups, the findings indicate that persons that get training have little more activities than those who do not get training, so that the contributions to growth are not much different. In words, political efficacy through self-esteem and motivation scores after training plays a little role in LDCs, in particular Cambodia.

As implied by previous literature, the point of investigating causations of human capital and growth lies in that such causal patterns might be correlated with the level of GDP and economic growth. A large number of studies found evidence consistent with an endogenous growth framework - human capital is the engine of growth - while others found the opposite or even reciprocal relationships. One question arises naturally. Is there any noticeable relation between human capital and the level of economic development and growth? More specifically, if the government expenditures on education are used as proxy for human capital, then does human capital cause growth? What if we test for causation in countries with different levels of growth and development? These questions once again challenge the validity of both human-capital-based endogenous growth theory and human capital measurements as part of human capital theory.

As an application of the endogenous growth theory, the human capital and growth causation is straightforward and relatively conclusive. In particular, the answer to such query is central to developing countries. Thailand, a country listed in this category, would clearly benefit from understanding the apparent patterns between human capital, measured by government spending on education, and economic growth. There exist policy differences whether such relation reconciles with the theory of endogenous growth. In other words, it is still plausible to see the reverse or even bidirectional causality in the case of Thailand. It might occur as the consequence of having moved up to the certain level of growth and development, thus resulting in better education. The higher quality of education can be determined by higher percentage of spending on education as compared to the GDP. This is presumably an increase in human capital investment, leading to more productivity and national income as well as a higher level of economic growth.

Having defined human capital either narrow or broad, by single or multiple measures, one had better bear in mind that the meaning should be ample, historically thorough, and practical. This might include giving an emphasis on various measurements such as cost-based, output-based, and lifetime-income-based. Thus, the main purposes of this study are to thoroughly explore the context of human capital, to specify various measurement approaches, and empirically test the causative directions between human capital and Thailand's economic growth. The findings would be the springboard for understanding the causal patterns as applying the same technique for other countries. One of the advantages is that we are able to compare the results and probably detect the patterns of causality when different levels of development and growth are taken into consideration. Such investigation is supposedly the subsequent research project. But, now let's focus on the present study.

The rest of this paper is organized as follows. The method and econometric model are encapsulated in the next section. It provides a review of related theoretical concepts and approaches for human capital measurement and how to estimate as well as how the results would be interpreted. This includes the sources of data, periods of data observed, and data description. The next section presents the results. And the last section is discussion, conclusion and recommendation.

\section{Method}

The methods corresponding to the objectives are described separately. This study employs both qualitative and quantitative methodologies as follows.

\subsection{A Review of the Concepts of Human Capital and Its Meaning}

This section uses a qualitative investigation method. Analytical comparison among the existing literature on human capital is the first step. This stage is to delineate the structure of human capital as well as explain how the scholar's viewpoints have evolved through time. An integration of the body of knowledge is performed in order to build one explanatory conceptual framework so that the scope of human capital is developed. After such synthesis stage, the validity of concepts is ensured through investigating current empirical studies relevant to this invented conceptual framework.

\subsection{Approaches for Human Capital Measurement}

This section begins with a qualitative investigation of the ways to measure human capital. The next step is explaining each approach for human capital measurement including analyses of the rational for each approach. Then, advantages and disadvantages are critically analyzed, approach by approach, including various aspect comparisons among different approaches. And a number of previous empirical studies concerning human capital 
measurement are discussed in detail as to ensure their validity and practicality.

\subsection{Causal Relationships between Human Capital and Thailand's Economic Growth}

This section is in essence a time-series macroeconomic analysis. The growth rate of gross domestic products as indicative of economic growth, the percentage of government spending on education to GDP as proxy for human capital, which could be separated by levels of education (if the data is available throughout) are variables of interest. Based on unit root test, all data are examined by Augmented Dickey Fuller test to see whether nonstationary problem is present. If variables are stationary, then proceed to the next step; otherwise, data differencing with appropriate lag number is needed to be certain that the estimation does not lead to spurious results. The variables are tested for the co-integration. If they do co-integrate, the unidirectional or bidirectional causation is identified using Granger causality test or other recently-developed tests if appropriate. Describe the procedures for selecting participants, including (a) the sampling method, if a systematic sampling plan was used; (b) the percentage of the sample approached that participated; and (c) the number of participants who selected themselves into the sample. Describe the settings and locations in which the data were collected as well as any agreements and payments made to participants, agreements with the institutional review board, ethical standards met, and safety monitoring procedures.

The data employed in this study are annually during the period 1980-2010, totaling to 31 observations. Sources of data are as follows. The GDP and GDP growth rate is from the Bank of Thailand and the percentage of government expenditures on education are obtained from the United Nations. All data are recalculated and utilized in terms of the current prices (billions of baht).

\subsection{The Econometric Model}

According to a framework of endogenous growth model, the production function takes the Cobb-Douglas form as the following.

$$
\ln Y(t)=\ln A(t)+a \ln K(t)+b \ln L(t)+c \ln H(t)+\varepsilon(t),
$$

where $\mathrm{Y}$ is GDP or output, $\mathrm{K}$ is the capital stock, $\mathrm{L}$ is labor, $\mathrm{H}$ is human capital, $\ln$ is natural $\log , \varepsilon$ is disturbance term, $a, b, c$, and $\ln A$, are coefficients. The coefficient in front of each variable is the elasticity of output with respect to that input. Such interpretation explicitly makes human capital an endogenous determinant of growth because if the stock of human capital increases by one percent, how many percentages the GDP rise, which is the same notion of growth. However, the objective of this section is to find the casual relationship patterns between human capital and economic growth, a prerequisite that needs to be verified is the existence of linear relationship as assumed by the econometric estimation method widely used, so called OLS (Ordinary Least Squares). In addition, according to the endogenous growth, the dependent and independent variables are set as follows.

$$
y g(t)=\alpha+\beta H C(t)+\psi(t),
$$

where $y g$ is the growth rate of GDP. $H C$ is the share of spending on education to GDP as proxy for human capital. $\psi$ is the disturbance term, $\alpha$ and $\beta$ are parameters to be estimated. After the linear relationship is established, then the standard processes used in time-series analysis are performed as mentioned earlier. Note that if the unit root problem (based on the Augmented Dickey Fuller test) is not present, cointegration test is performed to check whether any two macroeconomic variables are co-integrated. If they are, the causality test can be used to determine the causal relation patterns. To test for causality between human capital and economic growth of Thailand, an econometric technique that can verify such causations will be employed, typically the Granger causality test.

\section{Results}

This section provides the results of the study. First is to provide a theoretical review of the core concepts and scope of human capital. Second is to identify approaches for human capital measurement. And last is to investigate the causal relationships, if there exists, between human capital and economic growth of Thailand using the share spent on education to GDP as proxy for human capital. The results are the following, respectively.

\subsection{Human Capital Definitions and Its Scope}

Perhaps human capital is the crux of modern labor economics since it has long been known that labor can be regarded as both brain and brawn. However, the brain is much harder to measure; in fact, there is no consensus on the exact definition of Human Capital. To be able to define human capital in a meaningful way is actually a challenge. It should also reflect both what has been involving and the present society which is so complex. Why does it so hard to define it? Probably because it is multidimensional, keeps changing, and its role on social and 
economic dimensions can be comparable to a positive externality. Regardless of such difficulties, this part aims to provide the definition of Human Capital in a practical fashion by taking advantages of its development that is constantly changing through time, perhaps, broader and more abstract. The methods for qualitative analyses are comparison, explanation, and integration (synthesis). In addition to scoping the human capital, approaches for human capital measurement are analyzed using the qualitative analysis as well. It is to rationalize and express how to measure human capital. Next, the empirical investigation is provided as evidence to check the congruence of a concept of human capital, measured by the share of expenditures on education to GDP, with the economic growth of Thailand. The frontier of researches on human capital would be summarized, accordingly. As mentioned earlier searching for what it means by human capital is not an easy task since it is an endeavor to quantify something that qualitative intrinsically. In addition, its meaning keeps changing through time. However, dated back to Classical period, Adam Smith (1776) emphasized that human capital is a type of capital and education is important to the wealth of nations. He claimed that the educational expenses are as vital as those of expensive machines. This means the cost of education is considered as the indicator of such an investment in education. After the Classical times, Lewis (1954) compared human capital as "unlimited supply of labor." Later, Pigou raised the point that investment in human capital does exist. The connotation is that investment at least can be separated into physical investment and human capital. Jacob Mincer (1958) reiterated the importance of human capital investment. Schultz (1961) used the term "Human Capabilities" in the context of economic development and paid close attention to the need for the disentangle of human capital and physical capital. He also defined human capital as all useful skills and knowledge that is part of intended investment. More specifically, his examples are made clear about what it means by "Human Capital," so that it is worth the direct quote. "Much of what we call consumption constitutes investment in human capital. Direct expenditures on education, health, and internal migration to take advantage of better job opportunities are clear examples." (Investment in Human Capital, 1962, page 1)

Thus far, human capital has been perceived as several dimensions. In particular, it gives rise to an understanding that education is not the only form of human capital but a crucial one. That human capital investment centering on education and other forms which can be measured by their direct costs is also pivotal since it is a way to measure human capital that is essentially intangible. Moreover, the costs or expenses of investment imply both at present and in the future, which would be paid off later.

Around that time, Gary Becker (1964) turned human capital to the production scheme, which is considered a significant application and interpretation of human capital. He, in addition, made the comparison between human and machines that can be used to produce output in the same manner. In words, the methods of production are stressed in that additional investment leading to more output is similar to how the machines give rise to the output. Education, training, health among others are the crystal clear forms of such investment. Since then, the investment in human capital had been consistently underlined on these bases. The fruit of human capital can be, to certain degree, specified by the rate of return on human capital one owns.

Again, Becker provided a more insightful detail of human capital in that it can be distinctively separated into "specific" and "general." Specific human capital concerns skills or knowledges that are useful only to a single employer but general human capital is those useful to all employers. According to such separate viewpoints on human capital via training, a belief that human capital investment is risky emerges if it is deemed "general."

Romer (1986) and Lucas (1988) are the other two prominent scholars who contribute a great deal to this issue. Romer defined capital not only as factories, machines, tools, and the like, but also as the consequence of investment in research and development (R\&D), innovations, or ideas to produce new products. This leads to a new form of capital called "knowledge," which might be accumulated through time. Such capital can generate the positive externality that would benefit the economy and economic development by its ramification. Though not exactly the same, one of the Lucas's viewpoints dissimilar to Romer is the positive externality of knowledge. Lucas asserted further that advancement of knowledge and technological progress are hard to disintegrate so that they must be thought of a composite outgrowth from human capital. Technology bundled with the knowledge arising from human capital accumulation can be envisioned as two aspects. One happens without externality but the other comes with positive externality, which could benefit all people. That is, an increase in human capital accumulation, implying more advanced knowledge and technology, moves forward the economy and economic development.

Both Romer and Lucas basically focused on the external effects of human capital, generally the knowledge resulting from more human capital accumulation which in turn would generate more and advanced knowledge. Their models are based on the notion that human capital is an endogenous variable that can describe the economic growth and the marginal product of this input shall not and would never be zero, as a typical 
framework of endogenous or new growth theory. A way out is build a model that the returns to human capital be classified as "increasing returns to scale" or IRS. Consistent with defining human as such knowledge by nature, this would give rise to positive externality. Undoubtedly, the definition of human capital is influenced by the new growth theory, more specifically by the mechanisms of modeling and the need to be able to explain the real world phenomena.

With the advent of advanced technology, creative innovations, and new products, human capital is defined with the inclination as to "the knowledge with technological progress." As the term suggests, anything formerly defined seems to dwindle in its role as human capital. By contrast, anything closely fitted into that is a standout. For instance, in Lucas model, human capital can be thought of two different strands, one with that accumulated off-the-job training and another with that accumulated on-the-job training (learning by doing). This easily leads one to perceive a lesser role of formal education but a greater role of training as such the interpretation of human capital. Mankiw, another well-known contributor to human capital issue, has convincingly argued for defining "human capital" as that amount of knowledge, basically via studying, which is embedded with technology progress. He stated that since lifetimes are finite, there is an upper bound to the amount of human capital that can be accumulated. Thus, increasing human capital, say more years of schooling, may be able to be raised to some point up to the transition period in a growth model, but human capital accumulation cannot explain the growth at the steady state. This is to say knowledge cannot be accumulated without a bound. As such, in the context of the endogenous growth model, as it predominately impacts how the human capital definition should be. The point is that the amount of human capital accumulation might not be a strong candidate to explain the long-run economic growth aspect.

In a famous work by Mankiw, Romer, and Weil (1992), human capital is defined, interpreted, and measured by education - still, the way that model is built and other restrictions are of influence, making use of the percentage of the working-age-population that is still in secondary school as the rate of human capital accumulation. They admitted that using this variable has a number of flaws but arguably suitable in terms of the model setting. Once again, a variable concerning education is used as proxy for human capital. One question arises. Is it appropriate to define human capital narrowly, simply to follow the models, or desperately to conform to the availability of the world data? In the beginning of the twenty centuries, the Organisation for Economic Co-operation and Development (OECD) in 2001 announced and defined human capital as "The knowledge, skills, competencies and attributes embodied in individuals that facilitate the creation of personal, social and economic well-being." (OECD, 2001, 18) Furthermore, the OECD in 2011 has, in addition, provided its broader definition as the following. "It incorporates various skills and competencies that are acquired through learning and experience but may also include innate abilities. Some aspects of motivation and behavior, as well as the physical, emotional, and mental health of individuals are also regarded as human capital in this broader definition" (OECD, 2011). This broader view of human capital is consistent with a recent work by Polachek, Das and Thamma-Apiroam in 2013. Such congruence is that they have attempted to adopt the broader view and quantify them through complicated models and make use of rather up-to-date econometric techniques. Part of it is to explicate the innate ability both ability to learn and ability to learn which are used to be a persistent problem called "unobserved heterogeneity" due to the difficulty to pull them out. In addition to these hard-to-measure abilities, there are three more parameters to be estimated, all well known as cognitive abilities commonly used in psychology. In detail, they derive a tractable nonlinear earnings function which is estimated separately for each individual in the National Longitudinal Survey of Youth conducted in 1979 (NLSY79) data of the United States. These estimates yield five important parameters for each individual: three ability measures (two representing the ability to learn and one the ability to earn), a rate of skill depreciation, and a time discount rate. Moreover, they obtain a population wide estimate of the rental rate of human capital and illustrate heterogeneity in the production of human capital, and plot the distribution of these parameters along with NLSY79 reported AFQT scores. By utilizing these parameters, they can verify a number of untested theorems implied by the life-cycle human capital model. Also, they are able to show how these human capital production function parameters relate to cognitive ability, personality traits, and family background. Among results, they find that individuals with both a high internal locus of control and self-esteem exhibit greater ability, lower skill depreciation, and smaller time discount rates. Individuals inclined towards depression have higher time discount rates. Agreeable, open, conscientious and extrovert individuals have a greater ability to learn but not necessarily a greater ability to earn. Neurotic individuals have a lower ability to learn. Higher parental education is associated with a greater ability to learn, lower skill depreciation, and a smaller time discount rate. Educational stimuli are associated with higher ability. In contrast, growing up poor is associated with lower ability.

Clearly, from the above work, a number of never-been-measured-before concepts have been measured here. 
These together with other traditional definitions of human capital constitute a broader perspective on how one can define and quantitatively measure human capital. It can be considered a pertinent contribution in this area. Altogether, with the past developments of human capital definition, today another substantial consideration comes into play. That is, social capital. What is exactly social capital? To answer this, we first should understand that it is diverse and keeps changing over time, just like human capital. In addition, to define it requires a great deal of understanding and interpretation associated with networks, norms, externalities, especially the external returns. It seems that there exists a large part that both human capital and social capital have in common but one of the most distinct roots is the positive externality. As a result, human capital is currently defined and interpreted in the context of social capital as well. The previous attempts to provide human capital definition and its scope posit that there are various factors that influence what human capital may be comprehended. They are for instance the need to quantify it, the level of social and economic development, the model considerations, the level of technology, the empirical consistency as well as the availability, accessibility, and accuracy of relevant data, etc. The following chart (Figure 1) expresses the main definitional grasp of human capital that keeps evolving through time. Also, a comprehensive chart of human capital divided by cognitive ability and non-cognitive ability aspects is shown in Figure 2.

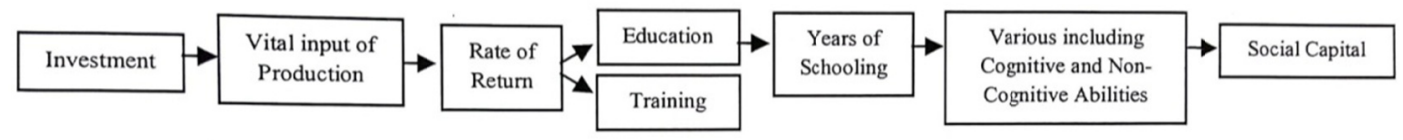

Figure 1. A chart showing the focus of human capital definition developments

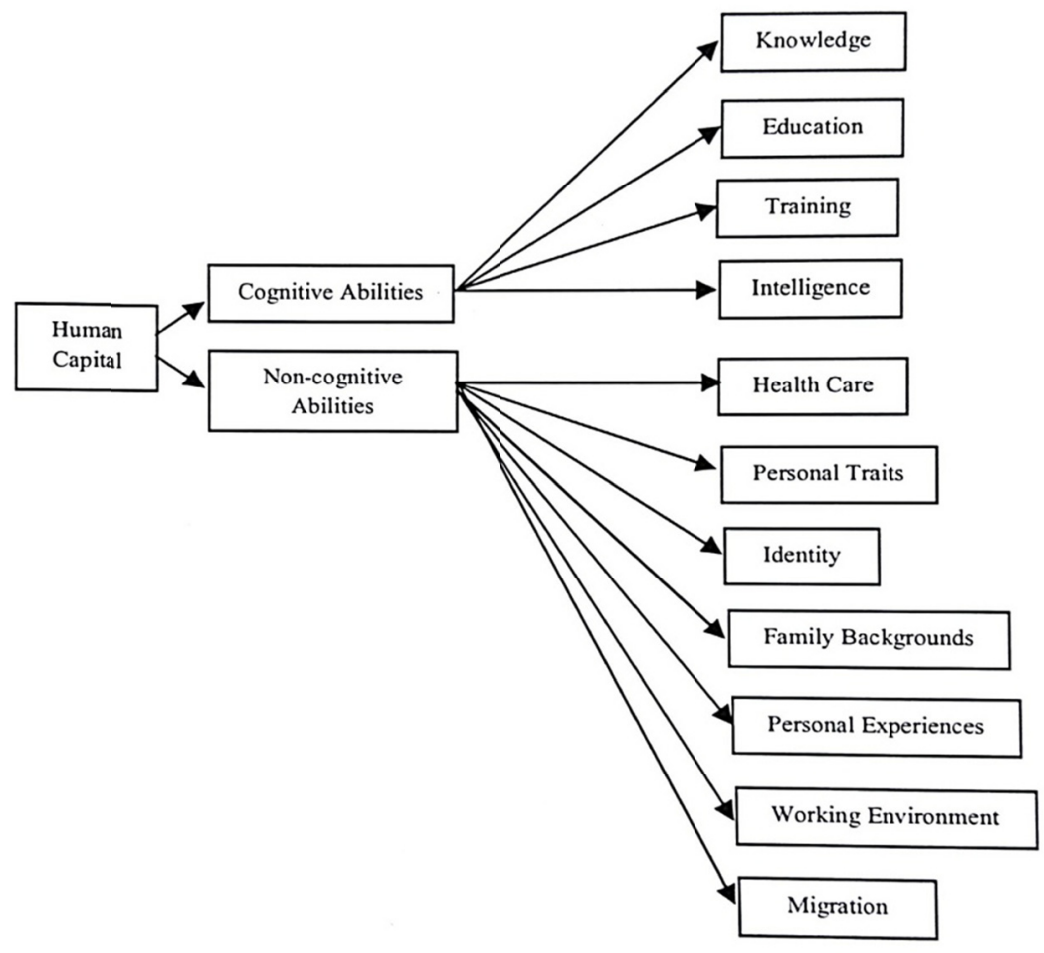

Figure 2. A Comprehensive chart showing the of human capital definition

According to Figure 1, we see that in the past human capital had been focused on as investment, afterwards as a vital input along with physical capital necessary for production. The education definition is provided as the rate return as well as training that comprises of general and specific schemes. Among others, one of the most popular interpretations is the years of education or schooling. Next, there are various attempts to fit into the human capital meaning which presumably gets broader and broader. This concerns cognitive and non-cognitive abilities. 
And currently the social capital is reasonably understood that it is somewhat similar to human capital. In part it is because they share the essential property of positive externality. According to Figure 2, we can separate the human capital into two distinct strands. One concerns cognitive abilities and the other concerns non-cognitive ones. Cognitive abilities deal with brain-based skills which include personal intelligence, advanced knowledge, education in a particular field and trainings, etc. For non-cognitive abilities, they concern health care, personal characteristics, identity, family backgrounds, personal experiences, working conditions set by employers, migration contribution, etc. Unlike the cognitive skills or abilities, non-cognitive abilities are much harder to measure in part it is difficult to enlist what they are. Therefore, when it comes to the measurement, the intrinsic problem is mainly from the non-cognitive. The next section, however, attempts to provide the basic approaches for human capital measurement.

\subsection{Approaches for Human Capital Measurement}

There are several viewpoints vis-à-vis the meaning of human capital. Different points of views almost always lead to incongruent measures. There are two strands which are indicators or non-monetary respect and monetary one. The indicator-based may be either qualitative or quantitative. The quantity might take the form of average years of schooling, educational attainment levels whereas the quality might be assessed by standardized or unstandardized test scores - overall combined or a specific section - class size and the ratio of student per teacher, for instance. The other strand, in contrast, is in the form of monetary term since human capital measures might be either direct or indirect estimates. The indirect estimates are derived from what can be inferred or the residual approach while direct estimates, resulted from direct estimations based on various components. The direct estimates can be divided into two major methods, the cost-based and the income-based approaches. These methods are standard and frequently used since if we consider human capital as a form of investment, then it is typical to think of its cost and returns, measured by income obtained from such investment. This regard has been backed up by theories and studies, so that the approaches for human capital measurement are provided as follows.

\section{1) The Cost-Based Approach}

This approach originally measures human capital by viewing it as the cost of production. However, this method is frequently referred to the sum of the depreciated value of past investment undertaken by individuals, households, firms, organizations, and governments, so sometimes it is called "backward-looking" approach. It also encompasses all of costs or expenses incurred as human capital has been producing such as the opportunity cost associated with attending school. Not only does this method include monetary outlays by the agents previously mentioned, but also take in non-market inputs such as time spent to education by students and other related persons. The cost-based measure is simple enough to measure when dealing with both private and public expenditures on education at aggregative level. Similarly, this method can legitimately incorporate the expenses of adult training, health, safety, as well as the values of in rearing and mobility. This is so because they are part of such costs of investment in human capital, too. In terms of mathematical formula, the cost-based approach can be expressed as the following.

$$
C=\sum_{j=1}^{r} c_{j}=\sum_{j=1}^{r}\left[\sum_{i=t=1}^{m} s_{i}^{e} /(1+r)^{i}\right]_{j}
$$

where $\mathrm{C}$ is the discounted total cost

$c$ is the expected cost in the year $\mathrm{j}$,

$s$ is the expected cost in the year $\mathrm{i}$

and $r$ is the discount rate

According to the structure of this cost-based approach, the flows of resources used for the purposes of human capital investment in education and other related parts can be measured. As a consequence, this approach is consistent with the income-based approach since one can easily envision it as the cost-benefit analysis, which is widely used when it nails down to investment.

Pros and Cons: One of the flaws pertaining to this method is that it should not be taken as an estimation of human capital since it is just a summation of historical costs and ignores the social costs that are invested in people. This means that if we aim to measure it more accurately, the stock of human capital by the cost-based approach should be separated into tangible and intangible. The tangible part consists of the costs required to produce the physical human being. In contrast, the intangible investment should aim at enhancing the quality or 
productivity of workers. They should include expenditures on health, mobility, education and training, and the opportunity costs of students attending school. This will provide an estimate of the resources invested in the education and other human capital respects, which can be useful for cost-benefit analyses. The bright side, though, it is quite easy to apply, owing to the ready availability of data both on public and private spending. Nevertheless, as is well known with physical capital, there is no relationship guarantee between investments and the quality of output. The value of capital is determined by the demand for it, not by the cost of production. This problem tends to be more serious with human capital per se.

\section{2) The Income-Based Approach}

This approach measures human capital by summing the discounted values of all future income streams that all individuals expect to earn throughout their working life or lifetime. Since this method is essentially the total expected returns on investment after the time deductions and they start to pay off when one begins working, sometimes it is called "forward-looking" approach. This forward-looking approach attempts to evaluate one's earnings profile, so that human capital valued is appraised at the market prices. This is because the labor market deems workers many factors, including abilities, efforts, education, and the institutional and technological structures of the economy. Mathematically,

$$
Y=\sum_{j=1}^{T} y_{j}=\sum_{j=1}^{T}\left[\sum_{t=1}^{m} w_{i}^{e} /(1+r)^{i}\right]_{j}
$$

where $\mathrm{Y}$ is the discounted total expected income

$y$ is the expected income in the year $\mathrm{j}$,

$w_{i}^{e}$ is the expected income in the year $\mathrm{i}$

And $r$ is the discount rate

According to this formula, there are some underlying assumptions worth mentioning. First, it is taken for granted that people invest in human capital just once in their life time. Second, the returns to investment would incur after one stops investing, before that and after the retirement age, such the returns are presumably zero. And international trade does not exist in this model.

Pros and Cons: One salient characteristic of this income approach is that it is forward-looking. Thereby, a dynamic economy that aims at measuring its income capacities would clearly get more benefit than the backward-looking cost approach. Nevertheless, this approach suffers from its consistency with the real world. For example, the model assumes that differences in wages can perfectly reflect differences in productivity. In reality, wages do vary, so income-based measures of human capital will be biased. Also, these measures are subject to the discount rate and the retirement age. Whether maintenance costs should be deducted is another drawback. There are controversies over this issue. Some scholars point out that this income approach has a serious problem due to not deducting maintenance costs from gross earnings, so some others attempt to account for this but still face difficulties. For instance, what kind of expenditure should be classified as maintenance, and how to account for economies of scale and 'public' goods when estimating per capita consumption for different members in the same household? Another weak point lies in that data on earnings are not as widely available as data on investment. This is especially true for developing countries, where the wage rate is often not adequately observable or even unreliable. However, a number of people flavors this approach because it simple to measure and it represents the notion that if if one has more human capital, he or she should earn more as well over the course of the lifetime.

\section{3) The Output-Based Approach}

This approach measures human capital by its output. In other words, several indicators that can sufficiently represent the stock of human capital as a whole or at least as a group might be employed as the proxy. It is important to note that this approach does not directly view human capital as accumulated. Rather, it tends to find a suitable indicator or index that reflects the amount of human capital of an economy or a group of people. They might be average years of schooling, literacy rate, enrolment rate, net enrolment, gross enrolment, or some other educational attainment indexes. Because of its variegated indicators, average years of schooling which is one of the most popular and easy-to-measure proxies for human capital following this output approach stand out. The formula can be expressed below.

$$
\bar{H}=\sum_{i} L_{i} H_{i},
$$


Where $\bar{H}$ is human capital, $L_{I}$ is the proportion of the labor force with the ith level of education and $H_{I}$ is the number of years of schooling associated with the ith level of education. Furthermore, educational attainment can be separated into several levels of education: no education, incomplete primary, complete primary, incomplete secondary, complete secondary and higher education - bachelors' degree or beyond.

Pros and Cons: Like other approaches, this output-based measure has a number of drawbacks. Firstly, if the school enrolment is used as the proxy, it would be problematic since the school enrolment is the flow but human capital is a stock per se. Secondly, when dealing with international data, the gross enrolment is used rather than the net because of conformity and availability. This would lead to an econometric issue called "measurement error." Nevertheless, its advantage includes the data availability, simple calculation, and easy interpretation and understanding.

\subsection{Estimation Results}

The last part of the results is through quantitative techniques and empirical evidence. This study uses time-series econometric models pertaining to unit root test, cointegration test, and Granger causality test. Key macroeconomic variables of Thailand employed in this study are GDP, growth of GDP, share of government's expenditures on education to GDP as proxy for human capital. The data used in this study is aggregate annual time series at constant prices during the period of 1980-2010. The statistical methods utilized are the Ordinary Least Squares Method (OLS) and the Granger causality test. Before applying the Granger causality, standard tests such as unit root and co-integration were performed as well. The yg is used as the dependent variable while $\mathrm{HC}$ is used as the independent. Running the regression yields the results as shown in Table 1.

Table 1. Regression results when $\mathrm{HC}$ is independent variable and yg is the dependent.

\begin{tabular}{cccccc}
\hline Variable & Coefficient & t-value & R-squared & p-value & F-statistic \\
\hline & & & 0.113 & & 3.192 \\
yg/alpha & 3.184 & 4.992 & & 0.000 & \\
HC/beta & 0.108 & 1.787 & & 0.086 & \\
\hline
\end{tabular}

According to Table 1, there exists a linear relationship at $10 \%$ level of statistical significance because the $\mathrm{p}$-value of HC/beta is less than 0.10 . Therefore, the next step is to test whether the series has a unit root process. The results are shown in Table 2.

Table 2. Unit Root test

\begin{tabular}{cccc}
\hline \multirow{2}{*}{ Variables in levels } & \multicolumn{2}{c}{ Variables in } & \multirow{2}{*}{ ADF value } \\
\cline { 2 - 3 } & ADF value & First Difference & \\
\hline $\ln (\mathrm{yg})$ & -3.710 & $\mathrm{D} \ln (\mathrm{yg})$ & $-8.088^{*}$ \\
$\ln (\mathrm{HC})$ & -1.322 & $\mathrm{D} \ln (\mathrm{HC})$ & $-7.817^{*}$ \\
\hline
\end{tabular}

Note: * sig. at $5 \%$ level

According to Table 2, the ADF value for the first difference in $\ln (\mathrm{yg})$ is -8.088 and the ADF value for the first difference in $\ln (\mathrm{HC})$ is -7.817 , so that both series do not have a unit root problem at first differencing. The Next step is to test for co-integration. The results are shown in Table 3.

Table 3. Co-integration test

\begin{tabular}{ccccc}
\hline $\begin{array}{c}\text { Null } \\
\text { Hypothesis }\end{array}$ & $\begin{array}{c}\text { Max. } \\
\text { eigenvalue }\end{array}$ & $\begin{array}{c}5 \% \\
\text { Critical Value }\end{array}$ & $\begin{array}{c}\text { Trace } \\
\text { Statistic }\end{array}$ & $\begin{array}{c}5 \% \\
\text { Critical Value }\end{array}$ \\
\hline None* & 87.752 & 15.410 & 100.606 & 14.070 \\
At most one & 12.905 & 3.760 & 12.905 & 3.760 \\
\hline
\end{tabular}

According to Table 3, the max eigenvalue is 87.752 and the $5 \%$ critical value is 15.410 , so that it indicates that these two series are co-integrated. The next step is to determine whether casual relationships exist. If so, which 
direction? However, it is theoretically impossible to claim that the growth rate definitely leads to the human capital or vice versa, so the empirical evidence following Granger causality test is then investigated. The specifications are as follows.

$$
\begin{array}{r}
\ln y g(t)=\gamma_{0}+\sum_{i=1}^{k+d} \alpha_{1 i} \ln y g(t-1)+\sum_{j=1}^{k+d} \beta_{1 j} \ln H C(t-1)+\varepsilon_{1}(t), \\
\ln H C(t)=\delta_{0}+\sum_{i=1}^{k+d} \alpha_{2 i} \ln H C(t-1)+\sum_{j=1}^{k+d} \beta_{2 j} \ln y g(t-1)+\varepsilon_{2}(t),
\end{array}
$$

Then, with maximal order of integration $(\mathrm{dmax}=1)$ and optimal lag $(\mathrm{k}=1,2,3)$,

$$
\begin{aligned}
& \ln y g(t)=\gamma_{0}+\sum_{i=1}^{k+1} \alpha_{1 i} \ln y g(t-1)+\sum_{j=1}^{k+1} \beta_{1 j} \ln H C(t-1)+\varepsilon_{1}(t), \\
& \ln H C(t)=\delta_{0}+\sum_{i=1}^{k+1} \alpha_{2 i} \ln H C(t-1)+\sum_{j=1}^{k+1} \beta_{2 j} \ln y g(t-1)+\varepsilon_{2}(t),
\end{aligned}
$$

The Granger causality test results are provided in Table 4.

Table 4. Granger causality test

\begin{tabular}{cccccc}
\hline Null Hypothesis & Lag & No. of Obs. & F-statistic & Prob. & Decision \\
\hline Yg does not Granger & 2 & 29 & 0.412 & 0.661 & Accept \\
Cause HC. & 3 & 28 & 2.720 & 0.070 & Reject* \\
& 4 & 27 & 1.525 & 0.237 & Accept \\
\hline \multirow{2}{*}{ HC does not Granger Cause } & 2 & 29 & 3.306 & 0.054 & Reject* \\
yg. & 3 & 28 & 2.419 & 0.095 & Reject* \\
& 4 & 27 & 2.520 & 0.077 & Reject* \\
\hline
\end{tabular}

Note: 1) No. of observations in this table is calculated after lag. 2) * sig. at 10\% level

According to the results shown in table 4, the hypothesis that yg does not Granger cause HC is accepted after 2 and 4 lags but rejected at $10 \%$ of statistical significance level after 3 lags. This means that the growth rate of GDP causes human capital. In this case, it indicates that as the economy grows after 3 years, it will induce a rise in the percentage of government spending on education to GDP. In other words, it takes about 3 years that the growth will affect such the spending. Conversely, the hypothesis that HC does not Granger cause yg is rejected after 2, 3 and 4 lags at 10\% of statistical significance level. This indicates that $\mathrm{HC}$ does cause economic growth at every lags. That is to say the higher share of spending on education to GDP, the higher economic growth rate is. Note that this keeps on occurring year after year.

\section{Discussion and Conclusion}

The results above are worth discussing. Like other developing countries, Thailand's economic growth depends on the percentage of spending on education to GDP. It is clear that to simulate growth, one way is to keep increasing the expenditure share on education to the GDP. This empirical result is coherent with the national social and economic development plan, so that the policies concerning educational development should be implemented urgently.

\subsection{Limitations and Comments}

Like all research, this study has some limitations as well. First of all, human capital is qualitative so that it is impossible to find a measure or a long list of measures that can accurately quantify it. This means that it's impossible to find any proxy that is free of flaws. In fact, every single proxy suffers from one or more shortcomings. In this study, there are at least two reasons why the share of spending on education to GDP is utilized as proxy for human capital. One is that this study employs both qualitative and quantitative analyses. For the quantitative scheme, it is lucid clear that the main focus is on an application to the endogenous growth theory through macroeconomic variables. It aims to investigate and distinguish the patterns of causal relation between human capital and economic growth of Thailand, so that such spending on education is considered suitable. One might point out some disadvantages of this variable. In Thailand case, the majority of expenditures are the salaries of teachers and lecturers in public schools and they cannot directly measure the student quality or educational accomplishments. Such viewpoint is not dissimilar to an understanding in a narrow spectrum and 
concomitantly it leads to a fallacy that underestimates the power of earnings. Let's analyze.

As well known, the earnings or income is frequently used as the proxy for human capital as the fruit of human capital investment. The earnings have been thoroughly analyzed and synthesized for the power and coherence of human capital measurement as upheld by Mincer and other distinguished scholars in the field of human capital, irrespective of some drawbacks. As such, using the expenditures on education is common and logical at least in theoretical perspective. In addition, when dealing with aggregative macroeconomic variables, one ought to keep in mind that not every aggregative variable would possess enough weight to be called "macroeconomic variable." In particular, as it comes to the causal relation investigation with the economic growth rate. Dividing it into smaller pieces either fails to capture the "education" as a whole, to make economic sense when interpreting the casual relations, or both. Moreover, due to the data limitations, it's not a discrepancy choice of human capital. Next, Thailand's educational system or management can be prominently divided into private and public like other countries. In general, it is strongly perceived or evidently realized that the quality of education privately managed is not equivalent to that managed by the public or the government. This is true for almost all levels, especially at high school and university. Thereby, it is to say that on average the quality of education administered by government is at worst equal or somewhat superior to that administrated by the privates. This claim might be invalid when considering at junior high school or lower levels. As such, the salaries of teachers and lecturers in public educational institutions can better represent the quality of students and educational attainments than those of private educational institutions. Of course, one might argue again that such better quality of education still does not directly represent the aforementioned overall education quality. The data used in this study, nonetheless, not only includes the salaries of the public school teachers but includes the expenditures on education for private schools as well, though partially. That is, taking into consideration of the data availability as well as previous explanations, the proxy for human capital used in this study has been carefully chosen and reasonably sound.

Some might raise another point that by definition human capital is the stock variable while the expenditures on education without a doubt are flow variables. They do not match in terms of quantitative weight. Nevertheless, no such thing could ever match human capital because it's qualitative not quantitative and something qualitative cannot be measured accurately per se. So the point is to look for a decent candidate for human capital not to indeed weigh it. Once again, as indicated the third objective of this study is to establish the casual relationships between human capital and economic growth. Using such expenditures on education, which are flows as proxy for human capital is perfectly consistent with the GDP, which is also a flow variable.

In summary, Human Capital has been identified as an indispensable factor of production and it becomes increasingly significant in terms of knowledge and capabilities embedded in labor either innate or later acquired throughout one's lifetime. For the definition of human capital developed and changed over time, it can be expressed both cognitive and non-cognitive abilities. The cognitive abilities basically are intelligence, advanced knowledge, education, training while non-cognitive abilities typically are personal traits, identity, family backgrounds, personal experiences, and working environment. The approaches for human capital measurement can be distinctively separated into three types which are cost-based, income-based and output-based. And the empirical evidence based on Granger casualty test as an application to human capital theory and endogenous growth theory indicates that Thailand needs to focus on education since it is a way to spur the economic growth. And as the economy grows at a certain level, there would be a reverse effect too that the growth might higher the human capital as measured by expenditures on education as percentage to GDP.

\subsection{Recommendations}

\subsubsection{Recommendations from This Study}

1. Since human capital definition is multi-dimensional and keeps changing, the uses, interpretations and measurements significantly fall back on the purpose of individual research. For example, if one wants to test the relation between human capital and economic growth, the definition and interpretation in macroeconomic sense is a necessity.

2. In general, to provide the definition of human, we need to consider a broader view, which includes social capital aspect as now it is clear that human capital does impact culture, society and economy in rather complicated and reciprocal fashion.

3. For the empirical test section, the results suggest bidirectional casual relationships between economic growth and human capital measured by the share of spending on education to GDP. However, the causality running from human capital to growth is much clearer. The policies that pay more attention to education and quality of education through more spending on education as the percentage to GDP should be promptly implemented. 


\subsubsection{Recommendations for Future Research}

1. For further study, the emphasis should be on the measurement of human capital since there are new methods to measuring it, thus leading to the new methodologies to study its effect on economic growth.

2. For the empirical test, this study presumably takes education as the main proxy for human capital basically because it is practical and the data is readily available. Nonetheless, there are a large number of well-measured and defined which can be used as the quantitative measure of human capital as well. The validity of the human capital and the endogenous growth theory might be challenged again.

3. This present study takes Thailand as a case study. However, there are over a hundred more countries to be examined by the same method, so that we can see the big picture of what kinds of relation between human capital and economic growth in the world. Further, the same can be done separated by different levels of development. Doing so might result in a clearer understanding of such relationships or some interesting relationship pattern suggested by the empirical results.

4. Apart from focusing on the casual relation between human capital and economic growth, there are some other interesting points to explore such as estimating human capital through the nonlinear earnings functions which can take a number of forms. Also, one can use cross-country data and compare the goodness of fit for those with the shapes of the production functions.

\section{Acknowledgments}

The author would like to thank the Department of Economics, Kasetsart University for the research grant and supports.

\section{References}

Arrow, K. J. (1962). The Economic Implications of Learning-by-Doing. Review of Economic Studies, 29(1), 155-173. http://dx.doi.org/10.2307/2295952

Barro, R. J. (1991). Economic Growth in a Cross Section of Countries. The Quarterly Journal of Economics, 106(2), 407-419. http://dx.doi.org/10.2307/2937943

Becker, G. (1962). Investment in Human Capital: A Theoretical Analysis. Journal of Political Economy, 70, 9-49. Retrieved from http://www.jstor.org/stable/1829103

Becker, G. (1964). Human Capital. New York: Columbia University Press.

Becker, G., \& Chiswick, B. R. (1966). Education and the Distribution of Earnings. American Economic Review, 56, 358-369.

Ben Porath, Y. (1967). The Production of Human Capital and the Life Cycle of Earnings. Journal of Political Economy, 75(4), 352-365. http://dx.doi.org/10.1086/259291.

Ben Porath, Y. (1970). The Production of Human Capital Over Time. Education, Income, and Human Capital, National Bureau of Economic Research, New York. Retrieved from http://www.nber.org/chapters/c3278

Berkowitz, R. (1998). One Point on the LSAT: How Much Is It Worth? Standardized Tests as a Determinant of Earnings. The American Economist, 42(2), 80-89.

Burt, C. L., \& Moore, R. C. (1912). The Mental Differences between the Sexes. Journal of Experimental Pedagogy, 1, 273-284.

Chiswick, B. R. (1967). Human Capital and Distribution of Personal Income (Ph.D. Thesis). Columbia University. Retrieved from http://www.jstor.org/stable/1821299

Chandra, A. (2010). Does Government Expenditures on Education Promote Economic Growth? An Econometric Analysis. Central University Working Paper. Retrieved from https://mpra.ub.uni-muenchen.de/25480/ 1/MPRA

Haley, W. J. (1971). Human Capital Accumulation over the Life Cycle (Ph.D. Dissertation). North Carolina State University.

Haley, W. J. (1973). Human Capital: The Choice between Investment and Income. American Economic Review, 63, 929-944.

Haley, W. J. (1976) Estimation of the Earnings Profile from Optimal Human Capital Accumulation. Econometrica, 44(6), 1223-1238. http://dx.doi.org/10.2307/1914256

Heckman, J. J., Lochner, L. J., \& Petra, T. E. (2008). Earnings Functions and Rates of Return. Discussion Paper 
Series No. 3310, IZA. http://dx.doi.org/10.3386/w11544

Herrnstein, R. J., \& Murray, C. (1994). The Bell Curve: Intelligence and Class Structure in American Life. New York: The Free Press.

Imran, M. et al. (2012). Relationship between Human Capital and Economic Growth: Use of Co-integration Approach. Journal of Agriculture and Social Sciences, 8(4), 135-138.

Johnson, T. (1970). Returns to Investment in Human Capital. American Economic Review, 60, 546-560.

Johnson, T. (1978). Time in School: The Case of the Prudent Patron. American Economic Review, 68(5), $862-872$.

Johnson, T., \& Hebein, F. (1974). Investments in Human Capital and Growth in Personal Income 1956-1966. American Economic Review, 64(4), 604-615.

Mincer, J. J. (1962). Human Capital and Growth. The American Economic Review, 91(2), 12-17.

Mincer, J. J. (1997). The Production of Human Capital and the Life Cycle of Earnings: Variations on a Theme. Journal of Labor Economics, 15(1), S26-S47. http://dx.doi.org/10.1086/209855

Mincer, J. (1970). Comments in the Production of Human Capital Over Time in Education, Income, and Human Capital. New York: National Bureau of Economic Research.

Monks, J. (1998). The Effect of Uncertain Returns on Human Capital Investment Patterns. American Economic Journal, 26(4), 413-418. http://dx.doi.org/10.1007/bf02299453

Neisser, et al. (1995). Intelligence: Knowns and Unknowns, Board of Scientific Affairs of the American Psychological Association.

Polachek, S. W. (1975). Differentials in Expected Post-Schooling Investment as a Determinant of Market Wage Differentials. International Economic Review, 16(2), 451-457. http://dx.doi.org/10.2307/2525825

Polachek, S. W., \& Siebert, W. S. (1993). The Economics of Earnings. New York: Cambridge University Press. http://dx.doi.org/10.1017/cbo9780511522062.004

Polachek, S. W. (2008). Earnings over the Lifecycle: The Mincer Earnings Function and Its Applications. Foundations and Trends in Microeconomics, 4(3).

Polachek, S. W., Das, T., \& Thamma-Apiroam, R. (2013). Heterogeneity in the Production of Human Capital. IZA Discussion Paper No. 7335.

Romer, P. M. (1986). Increasing Returns and Long-Run Growth. The Journal of Political Economy Economic Review, 96(October 1986), 1002-1037. http://dx.doi.org/10.1086/261420

Schultz, T. W. (1961). Investment in Human Capital. American Economic Review, 51(1), 1-17.

Uzawa, H. (1965). Optimal Technical Change in an Aggregate Model of EconomicGrowth. International Economic Review, 6, 18-31. http://dx.doi.org/10.2307/2525621

Wallace, T. D., \& Ihnen, L. A. (1975). Full-Time Schooling in Life-Cycle Models of Human Capital Accumulation. Journal of Political Economy, 83(1), 137-156. http://dx.doi.org/10.1086/260310

Wechsler, D. (1949). Manual for the Wechsler Intelligence Scale for Children. The Psychological Corporation, New York.

Weisbrod, B. A. (1972). Comment in Investment in Education: The Equity-Efficiency Quandary. Journal of Political Economy, 80(3), Part 2, S139-S141.

Wu, H. (2007). Can the Human Capital Approach Explain Life-Cycle Wage Differentials between Races and Sexes? Economic Inquiry, 45(1), 24-39. http://dx.doi.org/10.1111/j.1465-7295.2006.00002.x

Yildirim N., Deniz H., \& Hepsag A. (2011). Do Public Education Really Lead to Economic Growth? Evidence from Turkey. International Research Journal of Finance and Economics, 65, 12-24.

\section{Copyrights}

Copyright for this article is retained by the author(s), with first publication rights granted to the journal.

This is an open-access article distributed under the terms and conditions of the Creative Commons Attribution license (http://creativecommons.org/licenses/by/3.0/). 